\title{
A VEGETATION STUDY IN TWO SELECTED SITES OF MEETHIRIGALA FOREST RESERVE
}

\author{
CM Moonasinghe and MD Amarasinghe \\ Department of Botany, University of Kelaniya, Kelaniya
}

Meethirigala Forest Reserve, which is a patch of tropical evergreen rain forest, situated in the Gampaha District, bordering the Kegalle District, was studied, to characterise the forest with respect to vegetation structure. Floristic composition, stratification, species richness, species diversity and basal area of the vegetation were studied during a period of eight months commencing from February 2000. Data were collected from a site (A) presumed to be a less disturbed and relatively disturbed (B). Site A is situated within the area belongs to a monastery and hence is of restricted accessibility. Two plots each from the two sites, of the size, $30 \mathrm{~m} * 30 \mathrm{~m}$ were sampled.

Species richness was higher (42 species) in site B than in A (14). Diversity of species in site A was 2.08 and in site $B$ it was 3.35 . These figures showed a significant difference at $1 \%$ confidence level according to t-test. Species richness determined by Margalef's index shows a significant difference between the plots with site A, 2.0 and site B having 6.1. The evenness in site A (2.08) was lower than in site B (3.35). Endemism was higher in site A with $21.4 \%$ endemic species and in site B it was $11.9 \%$. The distribution of individuals in stem diameter $(\mathrm{dbh})$ classes was similar in both the sites with a reversed " $\mathrm{J}$ " shaped curve, indicating this forest community being composed mostly of smaller plants. However in site B there were no individuals representing largest class taken into consideration (i.e. $70-80 \mathrm{~cm}$ ) and it contains the most number of individuals in dbh class 3 (i.e. $20-30 \mathrm{~cm}$ ) whereas in site A dbh class 2 has the most number of individuals. Basal area figures in site $\mathrm{A}$ is greater with a $111.24 \mathrm{~m}^{2}$ of total basal area and a stand basal area of $0.94 \mathrm{~m}^{2}$. In site $B$ the values are $81.71 \mathrm{~m}^{2}$ and 0.74 respectively. However both the sites showed a reversed "J" curve with regard to basal area distribution, among individuals. Considering the height class distribution, class 1 (i.e. $<5 \mathrm{~m}$ ) showed a considerable increase in the number of individuals in site A than in site B. In site A, especially in plot 1 the understorey was of relatively low density and the stratification was disturbed. The average slope calculated was $0.38 \mathrm{~m}$ per meter in site A. It was $0.46 \mathrm{~m}$ per meter in site B.

Distribution of dbh in the community shows reversed "J" curve, a trend similar to that of Sinharaja rain forest community. This is true for both the sites in Meethirigala. In site A the number of individuals in the largest height class considered is similar to that of the Pasoh Forest Reserve in Malaysia. Pioneer species like Macaranga peltata and Schumercheria castaneaefolia are found in site B. Endemism figures are significantly lower in Meethirigala than in Sinharaja. Results of the present study suggest that, the natural structure of both the forest sites have been altered by human activity. Selective logging, destroying the forest for other non-timber products and encroachment of forestland have caused disturbance to the forest vegetation in site B. Site A appears more disturbed. This may be due to the fact that the two plots selected in sight A are located near the steam and they are more easily accessed by the villagers. It appears that both sites are disturbed more or less to a similar extent. 